\title{
The Higher Price of Cleaner Fuels: Market Power in the Rail Transport of Fuel Ethanol
}

\author{
Jonathan E. Hughes *
}

November 26, 2010

\begin{abstract}
This paper provides evidence of market power in the transportation of ethanol used in reformulated gasoline and alternative transportation fuels. I estimate a reduced form model for railroad route-level prices. My identification strategy instruments for railroad entry, controls for selection and explicitly models capacity constraints. A detailed understanding of this industry is important because U.S. environmental policies seek to substantially expand ethanol use. Evidence of market power may alter the types of policies pursued by lawmakers. I find that ethanol shipment prices are lower for more competitive routes. I also find evidence that railroads price discriminate based on environmental regulation at route destinations. Monopolist prices for shipments to carbon monoxide non-attainment areas are $3 \%$ higher than shipments to other destinations. This price premium falls sharply with increased competition. This suggests a perverse result where environmental regulation increases the price of a clean input.
\end{abstract}

*I thank Meghan Busse, Stephen Holland, Christopher Knittel, Douglas Miller, David Rapson, Victor Stango, four anonymous referees, and seminar participants at the College of William and Mary, the Colorado School of Mines, Iowa State University, North Carolina State University, Pennsylvania State University, the University of California Energy Institute, the University of California Santa Barbara, the University of Colorado at Boulder, the University of Michigan, UNC Chapel Hill, UNC Greensboro, and the University of Tennessee for helpful discussions. All remaining errors are my own. I thank Michael Nicholas for assistance with GIS programming. I am grateful for financial support from the Sustainable Transportation Energy Pathways (STEPS) program and the UC Davis Institute of Transportation Studies.

University of Colorado at Boulder, Department of Economics, 256 UCB, Boulder, CO 80309; email: jonathan.e.hughes@colorado.edu 


\section{Introduction}

Each year motor vehicles in the U.S. consume over 10 billion gallons of fuel ethanol. ${ }^{1}$ Used primarily in ethanol blended gasoline, biofuel advocates argue that ethanol reduces air pollution and greenhouse gas emissions, supports local agriculture and, in times of high oil prices, is a cost-effective alternative to petroleum. Because of these and other factors, the federal Renewable Fuel Standard (RFS) seeks to double or triple ethanol consumption over the next decade. ${ }^{2}$ New climate change policies such as a national carbon cap and trade system or low carbon fuel standard may further accelerate the growth in ethanol consumption.

Produced primarily in the U.S. Midwest, fuel ethanol is shipped via rail to demand centers in the eastern and western United States. Given the long distances, the ethanol transportation market is dominated by a small number of railroads who operate large multi-state networks. Most routes are highly concentrated with one or two firms competing at the route endpoints. In many cases, the role of alternative modes such as truck or barge transport is limited. Together, these conditions suggest considerable potential for market power in ethanol transportation. Furthermore, ethanol policies themselves may result in higher prices by providing opportunities for railroads to price discriminate among customers.

This paper investigates whether railroads exercise market power in ethanol shipments. I exploit a cross section of shipment-level prices collected from the pubic ethanol tariffs from five of seven North American Class I railroads. ${ }^{3}$ These prices are combined with detailed geographic information system (GIS) data that describe each firm's rail network, control variables as well as the locations and characteristics of ethanol plants.

The empirical model examines whether prices vary based on the level of competition at route endpoints. I use the number of firms participating at the route endpoints as an indication of the level of competition. This approach is similar to Schmidt (2001). However, Schmidt treats the number of firms as exogenous and ignores the possibility of capacity constraints as an explanation

\footnotetext{
${ }^{1}$ The U.S. Renewable Fuels Association (2010) estimates 2009 ethanol demand at 10.8 billion gallons. Domestic production in 2009 is estimated as approximately 10.8 billion gallons.

${ }^{2}$ The Energy Independence and Security Act of 2007 passed by the U.S. Congress establishes the RFS and requires production of 36 billion gallons of biofuel by 2022. The vast majority of this new biofuel is expected to be ethanol.

${ }^{3}$ Railroad classes are a designation based on operating revenue assigned by the U.S. Surface Transportation Board. Additional information on the characteristics of the Class I railroads is provided in Section 2.
} 
for the correlation between prices and firm participation. Because railroad participation may be endogenous, I instrument for the number of firms at the route endpoints using data from the 1900 U.S. census. To account for the possibility of railroad capacity constraints, I use detailed geographic data on rail traffic density as a measure of route congestion. In addition, I control for cost and demand characteristics using route distance, railroad effects, and origin and destination state effects. I find that ethanol shipment prices are lower for more competitive routes. On average, prices decrease by $3.4 \%$ for each entrant at the route origin.

If consumers are heterogenous, firms with market power may be able to increase producer surplus through price discrimination. Environmental regulation, specifically carbon monoxide nonattainment designation, may introduce an important source of consumer heterogeneity. Since the 1990 's, the federal government has designated counties with high carbon monoxide levels as "CO non-attainment areas." Many of these counties mandate the use of ethanol blended gasoline as part of a strategy to improve air quality. ${ }^{4}$ These blend rules may create markets in which the demand for ethanol is very inelastic. Furthermore, firms are able to identify these areas of inelastic demand via their non-attainment status.

I investigate this hypothesis by estimating the relationship between shipment prices and nonattainment status at route destinations. Monopolist prices are, on average, $3.1 \%$ higher at destinations located in $\mathrm{CO}$ non-attainment areas. The price premium decreases sharply with increased competition. For each additional entrant, the price premium falls by $2.3 \%$. It is unlikely that these effects are the result of railroad capacity constraints in non-attainment areas. Furthermore, a simple falsification exercise finds that rail prices for other commodities are not systematically higher in non-attainment areas.

This analysis adds to the empirical literature on price discrimination in the transportation sector beginning with Borenstein (1991) and Shepard (1991) in retail gasoline markets and Borenstein and Rose (1994) in airline markets. ${ }^{5}$ The approach adopted here is similar in spirit to Stavins (2001) and Busse and Keohane (2007).

\footnotetext{
${ }^{4}$ Examples include: Los Angeles, CA; El Paso, TX; Denver, CO; Missoula, MT; and Phoenix, AZ.

${ }^{5}$ Borenstein (1991) finds evidence of price discrimination based on search costs in the market for leaded gasoline during the early 1980s. Shepard (1991) investigates price discrimination based on service quality (self and full-service) in retail gasoline stations. Borenstein and Rose (1994) differentiate between price dispersion due to variation in costs and dispersion due to discriminatory pricing by regressing the Gini coefficient of fares on cost and market structure variables.
} 
Stavins (2001) documents price discrimination in airline tickets that increases with the level of competition. The author uses a reduced form model to study discounts due to fare restrictions. Discounts are found to be smaller on routes with higher market concentration. Busse and Keohane (2007) study price discrimination in rail shipments of low-sulfur coal to power plants under the 1990 Clean Air Act Amendments. The authors find that railroads do in fact practice price discrimination based on environmental regulation and geography. Prices increase for deliveries to regulated electricity plants relative to non-regulated plants. The price increases are less for electricity plants further from the low-sulfur coal mines where compliance options are more flexible. Busse and Keohane use panel data and exploit geographic variation, temporal, and cross-sectional regulatory variation to identify price discrimination. In contrast, I use cross-sectional variation in environmental regulation and competition at the route endpoints.

There is a substantial literature which investigates pricing in rail markets. A large number of studies have focused on the effects of railroad deregulation on pricing. While not an exhaustive list, prominent examples include Boyer (1987) and McFarland (1989) on average rail rates, MacDonald (1987) and MacDonald (1989) on grain shipment prices, and Burton (1993) and Wilson (1994) on shipment pricing for a variety of commodities. For a thorough review of this literature the reader is referred to Ellig (2002). More recently, a number of studies have explored that nature of market power in rail markets. Schmidt (2001), using a cross-section of city-level data, finds that rail prices increase and shipments decrease as the number of firms serving route endpoints decreases. Atkinson and Kerkvliet (1986) estimate rents to railroads transporting low-sulfur coal during the early 1980s. Friedlaender (1992) and Kunce, Hamilton and Gerking (2005) estimate price cost margins. This paper investigates an important new market, ethanol transport, and employs a more robust identification strategy than used in previous studies.

This paper also contributes to the existing literature on ethanol policy. Current studies focus primarily on the supply and demand for fuel ethanol, environmental impacts and the economic effects on related markets. Rask (1998) estimates reduced form models for ethanol supply and demand using state-level consumption data. Anderson (2010) estimates ethanol demand using station-level prices and quantities in Minnesota and uses his estimates to conduct a policy simulation of a renewable fuel standard. Farrel et.al (2006) investigate energy and greenhouse gas emissions and Searchinger et.al (2008) estimate emissions of ethanol production processes. The costs of ethanol production have been studied by McAloon et.al (2000) and Kwiatkowski et.al (2006). 
McNew and Griffith (2005) study the impact of ethanol plant entry on local grain prices. While each of these areas is important to the evaluation of ethanol policy, none of these papers have focused on the interaction between ethanol policies and rail markets.

Finally, there are also important complementarities between the present application and the literature on empirical models of entry and market structure beginning with Bresnahan and Reiss (1991) and Berry (1992). These models typically combine a structural approach with cross-sectional data to estimate the relationships between the number of firms participating in a market (or entrants) and profits. Berry and Reiss (2007) provide a thorough overview of this literature. In contrast to these models, the reduced form approach adopted here does not enable one to infer profits or the level of competition directly from railroad participation. However, many important policy questions relate to the effects of entry and environmental regulation on prices. The analysis that follows enables one to estimate these relationships while requiring less restrictive assumptions.

The remainder of the paper is organized as follows. Section 2 provides an overview of ethanol use in the U.S., ethanol production, and the structure of the U.S. ethanol rail transportation market. Sections 3 and 4 describe the data and empirical approach used in this analysis. The main results are presented in Section 5. Section 6 describes several robustness checks and Section 7 concludes.

\section{Ethanol in the U.S.}

\subsection{Drivers of demand}

Historically, the use of ethanol as a transportation fuel has been driven by state and federal policies. In the U.S., fuel ethanol is seldom used on its own but rather in blends with gasoline. There are three main applications that can be classified according to the relative quantities of ethanol and gasoline used in each blend.

First, ethanol is used in reformulated gasoline as an "oxygenate" to reduce motor vehicle emissions, namely carbon monoxide $(\mathrm{CO})$. Pollutants such as carbon monoxide $(\mathrm{CO})$ are the result of incomplete fuel combustion. Oxygenates are compounds that when blended into fuels increase oxygen content and improve combustion. Typically, ethanol used for this purpose is blended with gasoline at several percent ethanol by volume. Federal reformulated gasoline containing $2 \%$ oxygen 
(from ethanol or other oxygenates) was mandated until 2006 in approximately 130 counties. $^{6}$ An additional 65 counties opted-in to this program.

Second, fuel ethanol is used as a gasoline replacement. In modern passenger vehicles, ethanol can be readily substituted for gasoline in quantities as high as $10 \%$ to $20 \%$. The term "gasohol" is often used to describe blends with between $5.7 \%$ and $10 \%$ ethanol by volume. In many instances, gasohol mandates or incentive programs have been created by the federal and state governments as a means of supporting local agriculture or reducing petroleum consumption. ${ }^{7}$ Ethanol blends of this type may also be the result of so-called "economic blending" on the part of fuel suppliers when low ethanol prices relative to gasoline favor substitution.

Finally, ethanol is used as an "alternative fuel" in vehicles designed to burn ethanol instead of, or more commonly, in combination with a small amount of gasoline. The distinction between this and gasohol blends is the relatively high proportion of ethanol in the blended fuel. The standard formulation in the U.S. is E85 which contains $85 \%$ ethanol and $15 \%$ gasoline by volume. Flex fuel vehicles (FFV's) are designed to use E85, pure gasoline or a combination of the two fuels. However despite the availability of FFV's, E85 fueling stations are still relatively scarce. According to the U.S. Department of Energy (2008) there were approximately 1,400 E85 fueling stations in the U.S. compared with around 150,000 gasoline fueling stations.

Climate change policy is a new and increasingly important driver of ethanol demand. Compared with conventional fuels, ethanol can result in lower emissions of carbon dioxide and other greenhouse gases. Policies such as the federal renewable fuel standard (RFS) are at least in part motivated by the desire to reduce environmental externalities due to climate change. In California and several other states, low carbon fuel standards (LCFSs) have been enacted to reduce carbon emissions from the transportation sector by implicitly subsidizing cleaner fuels, (Holland, Hughes and Knittel (2009)). These policies are likely to result in large increases in the quantity of ethanol consumed in both gasohol and E85 type blends over the coming years.

Most of these applications create demand for ethanol in cities with large numbers of motor vehicles and fueling stations. Air quality concerns in particular have tended to create centers

\footnotetext{
${ }^{6}$ Oxygenation requirements for federal RFG were dropped in 2006 though many counties continue to use ethanol.

${ }^{7}$ For example, the U.S. government awards an ethanol blender's credit of 51 cents per gallon of ethanol used in transportation fuels. A partial list of state programs includes Minnesota which grants a wholesaler credit of 15 cents per gallon of ethanol used to make gasohol, Montana, Nebraska and North Dakota which grant credits of 30 cents, 18 cents and 40 cents per gallon, respectively.
} 
of ethanol demand in large urban areas, typically on the East and West coasts. However, U.S. ethanol production is mainly centered in the Midwest. Over 95\% of U.S. ethanol plants surveyed in Ethanol Producer Magazine (2008) use corn as a feedstock. Kwiatkowski et.al (2006) estimate corn represents approximately $75 \%$ of the production cost of ethanol. A major by-product of the production process is animal feed in the form of distiller's grains. As a result, the majority of ethanol plants are located in the Midwestern U.S. in areas of high corn and cattle production. Figure 1 shows the locations of ethanol production facilities and destinations for ethanol shipments. The geographic distribution of supply and demand creates a major market for ethanol transportation.

\subsection{Rail transportation}

A recent U.S. Department of Agriculture (2007) report estimates that approximately $60 \%$ of ethanol in the U.S. is transported by rail, $30 \%$ by truck and $10 \%$ by barge. Unlike petroleum, ethanol is difficult to transport via pipeline due to problems with corrosion and water absorption. Truck transport typically occurs over short distances or when relatively small quantities are required. Barge transport on the Mississippi River, Hudson River and Great Lakes is an option for plants or rail terminals located near these bodies of water. ${ }^{8}$ However for most routes, rail is the preferred mode of transportation and the role of outside options is limited.

The most likely destinations for ethanol shipments are petroleum distribution terminals. Gasoline is typically transported from the refinery to local distribution terminals by pipeline or barge. Because ethanol blended gasoline is difficult to transport via pipeline, blending of ethanol and gasoline usually occurs at the terminal. The blended fuel is then delivered to retail stations by tanker truck.

Ethanol is transported by rail in 30,000 gallon tank cars. Shipments are arranged by the ethanol producer, customer or by a third party marketer. Both single car and unit train shipments are common. An ethanol unit train consists entirely of ethanol tankers and typically contains 80 to 90 cars traveling between a single origin (or gathering location) and destination. Because this type

\footnotetext{
${ }^{8}$ The USDA (2007) identifies major terminals located in: Albany, NY; Chicago, IL; Houston, TX; New Orleans, LA; and Sauget, IL. Unfortunately, I lack detailed data on barge shipments for the ethanol plants in my sample and cannot directly measure the effect of water transport on rail prices. Furthermore, not all ports are suitable for transporting ethanol. Including a dummy variable in the base model for whether an ethanol plant is within several miles of any port suggests rail prices are higher near navigable waterways but that the effect of railroad entry on rail prices is larger.
} 
of movement avoids the inefficiency of assembling or disassembling a train of cars from multiple locations, prices for unit train shipments are lower than single car shipments. ${ }^{9}$ However, unit trains are only suitable for the largest volume producers and customers. In my conversations with railroads, representatives also described a rigorous certification process for unit train facilities to verify, among other things, sufficient capacity for handling and unloading tank cars. ${ }^{10}$ Because the number of destinations served by unit train is still a small share of total destinations, this paper focuses on prices for single car shipments.

Recent estimates for the volume of ethanol transported by rail are difficult to obtain. The Association of American Railroads (2008b) reports that 96,000 carloads of ethanol were shipped in 2006. The USDA estimate of a $60 \%$ share suggests that approximately 3.9 billion gallons of ethanol were shipped by rail in 2007. At 30,000 gallons per car, this implies a total of 130,000 shipments in 2007. ${ }^{11}$ At 2008 prices, this implies a market of approximately $\$ 600$ million.

Of the more than 500 freight railroads operating in the U.S. in 2006, the vast majority of ethanol was shipped by a few firms. The Association of American Railroads (2008b) estimates that $80 \%$ to $85 \%$ of ethanol shipments originate on "Class I railroads." The seven Class I railroads are the largest carriers in terms of revenue as defined by the Surface Transportation Board. These firms accounted for approximately $70 \%$ of industry mileage and approximately $90 \%$ of industry revenue in 2006 according to the Association of American Railroads (2008a). This group includes Burlington Northern Santa Fe (BNSF), Canadian National (CN), Canadian Pacific Rail Service (CPRS), CSX Transportation (CSX), Kansas City Southern (KCS), Norfolk Southern (NS) and the Union Pacific Railroad (UP). Class I railroads typically own tracks in many states and operate long-haul routes between major cities. Given the large distances that ethanol is transported from plants in the Midwest to destinations on the Gulf, East and West Coasts, the Class I railroads are the most likely carriers for these shipments.

This paper focuses on ethanol shipments that occur on Class I railroads. Given that these firms

\footnotetext{
${ }^{9}$ The USDA (2007) estimates that a unit train can make a return trip 30 times a year as compared to 12 times a year for single car shipments. This reduces inventory carrying costs on the part of shippers and capital and operating costs for the railroads.

${ }^{10}$ For example, the Watson terminal in Southern California has the capacity to unload a 95-car (2.85 million gallon) unit train in a 24-hour period, http://www.us-dev.com/l_lomita_rail_terminal.htm. On average, this facility receives a new unit train every 3 to 4 days http://www.bnsf.com/media/news/articles/2004/09/2004_09_28a.html.

${ }^{11}$ Though a growing business, ethanol represents a small share of total rail shipments. Association of American Railroads (2008a) estimates put the total shipments of class I railroads at approximately 31.5 million per year implying that ethanol shipments are currently less than $1 \%$ of total traffic.
} 
control the majority of the market and that price data are more difficult to obtain for smaller railroads, this seems a reasonable simplification. Furthermore, the services that smaller firms provide are in many respects different from those provided by the Class I railroads. Regional "short-line" railroads move shipments between ethanol plants and interchanges with Class I carriers. Smaller firms also participate in state or regional markets on shorter routes suited to their more limited rail networks.

\subsection{Price discrimination based on environmental regulation}

Under the Clean Air Act of 1990, counties exceeding minimum air quality standards for specific pollutants are designated as "non-attainment areas." These areas are required to take steps to reduce vehicle travel, adopt emissions controls or require cleaner burning gasoline. The types of actions taken depends in part on the specific pollutants contributing to non-attainment status. In regions designated as carbon monoxide $(\mathrm{CO})$ non-attainment areas, a common approach has been to introduce oxygenated gasoline. Since many states have phased out the use of MTBE (methyl tertiary butyl ether), ethanol is the most common oxygenate.

In the past, winter oxygenation was required in $24 \mathrm{CO}$ non-attainment areas according to the U.S. Environmental Protection Agency, 2005. ${ }^{12}$ Some of these regions have since relaxed this requirement listing oxygenation as a "contingency measure." Nevertheless, many of these regions may still be expected to use oxygenated gasoline. This is because gasoline used in these areas has been specially formulated to allow for blending with ethanol and meet state and federal gasoline content regulations. ${ }^{13}$ Switching to another gasoline formulation often requires physical changes to refineries or additional transportation costs to import fuel from more distant refineries. These additional costs may prevent some regions from switching fuels despite changes to local regulations. ${ }^{14}$

\footnotetext{
${ }^{12}$ Typically, oxygenation is most important during the winter months in order to help reduce CO levels while avoiding contributing to smog formation.

${ }^{13}$ Oxygenation with ethanol increases octane and aids in the reduction of toxic compounds. Without ethanol, cleaner gasoline with higher octane must be substituted in order to meet the necessary fuel specifications. In addition, gasoline that is to be blended with ethanol must have a lower Reid Vapor Pressure (RVP) because adding ethanol increases the RVP of the blended fuel.

${ }^{14}$ In California for instance, oxygenation is not required during the summer months under California's state gasoline content regulations. Oxygenation was required under federal law in California until 2006. However since the oxygenation requirement was lifted, California has continued to use oxygenated fuel.
} 
One may expect the price elasticity of demand for ethanol, and hence ethanol shipments, to be less elastic in non-attainment areas. Conceptually, ethanol consumption in non-attainment areas is determined by the total level of gasoline consumption and ethanol blending proportions specified by oxygenated fuel rules. In these markets, ethanol and gasoline are perfect complements in the production of oxygenated fuel. Since ethanol represents a small fraction of the blended fuel, the price elasticity of ethanol demand is essentially the price elasticity of gasoline demand. Most estimates of the price elasticity of gasoline demand are quite small. ${ }^{15}$ In reality, the availability of transportation options means that the elasticity with respect to rail prices may be somewhat larger than the price elasticity of gasoline demand. However to a first approximation, transportation options should be uncorrelated with non-attainment status.

In markets outside of non-attainment areas, ethanol may be primarily used in gasohol or E85 blends. In this case, ethanol is acting as a substitute for gasoline, and demand depends on the relative prices of gasoline and ethanol. Anderson (2010) estimates average elasticities on the order of 2.5 to 3.5. This suggests demand for ethanol rail shipments may be more elastic outside of non-attainment areas.

If non-attainment status allows firms to distinguish between these different types of consumers, railroads with market power may be able to practice third-degree price discrimination in ethanol markets. Consider a market served by a single railroad. Assume the monopolist is able to divide the market into consumers of each type based on non-attainment status, but is unable to discriminate within a group. For simplicity assume marginal costs are constant and equal across groups. Under standard assumptions, optimal pricing results in the inverse elasticity rule (1) where prices for group $i$ are higher if the price elasticity $\epsilon_{i}$ is smaller in magnitude.

$$
\frac{P_{i}-M C}{P_{i}}=-\frac{1}{\epsilon_{i}}
$$

In markets with multiple railroads where firms behave non-cooperatively, a natural assumption is that increasing the number of competitors will decrease prices, all else equal. For instance, in the case of Cournot competition, it is straight-forward to show that average price-cost margins can be represented as an inverse elasticity rule analogous to (1) shown as (2) below, where $s_{j}$ represents the market share of railroad $j$. For symmetric firms, price-cost margins vary with entry as $1 / N$,

\footnotetext{
${ }^{15}$ For a summary of short and long run gasoline demand elasticities see Hughes, Knittel and Sperling (2008).
} 
where $N$ is the number of competitors.

$$
\frac{P_{i j}-M C}{P_{i j}}=-\frac{s_{i j}}{\epsilon_{i}}
$$

Higher prices in non-attainment areas that depend on the number of competitors suggests the presence of market power. Of course, it could also be the case that the cost of shipping ethanol to CO non-attainment areas is different than the cost to ship ethanol to other destinations. ${ }^{16}$ Under these circumstances, an observed difference in prices would not necessarily be an indication of market power. The empirical model described below attempts to differentiate between these two effects.

\section{Data}

The data used in this analysis consist of a cross section of ethanol shipment prices for five North American Class I railroads. The unit of observation is a railroad-route pair. These data provide a snapshot of ethanol rail prices during the first quarter of 2008. ${ }^{17}$ Price data were combined with detailed geographic information on the U.S. railroad network including track length, location, traffic density and ownership. Additional explanatory variables were collected from a variety of U.S. government agencies.

\subsection{Ethanol shipment price data}

Single-car ethanol price data were collected from the public tariffs of five Class I North American railroads. For the two remaining railroads the locations of origins and destinations of ethanol shipments are known, though prices were not available. ${ }^{18}$ The public tariffs represent the "advertised" price for transporting a single tanker car (30,000 gallons) between an origin (e.g., Iowa City,

\footnotetext{
${ }^{16}$ For example, if the seasonality of oxygenate demand results in higher congestion or longer turnaround times for unloading tank cars.

${ }^{17}$ While tariffs from other periods are available, the data collection process was extremely time-consuming due to the large number of individual tariffs and substantial differences in formats across railroads. As these data were collected by hand, creating a panel of price data would be very costly.

${ }^{18}$ The railroads that report public ethanol tariffs are: Burlington Northern Santa Fe (BNSF), Canadian National(CN); CSX Transportation (CSX); Norfolk Southern (NS); and the Union Pacific Railroad (UP). The Canadian Pacific Rail Service (CPRS) and Kansas City Southern (KCS) do not publish public ethanol tariffs. Citations for the public ethanol tariffs are given in the bibliography.
} 
IA) or origin group (e.g., Southeastern Iowa) and a given destination (e.g., Los Angeles, CA) or destination group (e.g., Southern California).

When origin or destination cities are grouped, cities within the group are assigned the same prices. ${ }^{19}$ In some cases, a railroad's tariffs are listed by destination state only and no prices for individual destinations are given. ${ }^{20}$ In these cases, I assign prices to individual cities in the destination state in the following manner. For railroad $i$ and state $j$, I define a set of possible destination cities as all cities within state $j$ having a population greater than 100,000 persons. Then, I exclude destination cities that do not fall on railroad $i$ 's rail network. ${ }^{21}$

Since the advent of the Staggers Rail Act of 1980, railroads have been permitted to negotiate private contracts for the shipment of goods. In my discussions with the railroads, firms differ in their use of private contracts with some firms relying exclusively on public prices, some negotiating only private contracts and some employing a mix of both types of prices. One manager stated that the western railroads, BNSF and UP, use only public prices while the eastern railroads, CN, CSX, KCS, NS and CPRS are more apt to utilize private contracts.

The lack of data on private contract posses two challenges for this analysis. First, private rates negotiated by individual shippers are presumably lower than those contained in the public tariffs. Therefore, the public tariffs represent an upper bound on the actual price paid for an ethanol shipment. Second, since only advertised prices are observed and not actual transaction prices, the existence of a public tariff does not guarantee that any ethanol is actually shipped at that price. ${ }^{22}$

To increase the likelihood that actual shipments occur on the routes with published public tariffs, I further restrict my sample by requiring the following: valid origin cities contain an ethanol production facility or serve as an interchange depot between rail carriers; and valid destination

\footnotetext{
${ }^{19}$ The implications of price grouping on the estimated standard errors are discussed in Section 4.2.

${ }^{20}$ In addition, BNSF uses a state group for origins in Illinois. Prices for this group are excluded from the analysis. Results are qualitatively similar to those presented below when ethanol plants and interchanges in Illinois are included as potential origins.

${ }^{21}$ Excluding destinations that are part of a destination state-group results in parameter estimates that are very similar to those presented below.

${ }^{22}$ This situation is similar in many ways to Internet price data. In their study of Internet book sales, Chevalier and Goolsbee (2003) show that sales weighted-average prices are significantly different from price averages that weight all books equally. These differences can affect the conclusions one draws from price dispersion online or from relative price differences between online and traditional retailers. Without ethanol quantity data, it is impossible to weight the observed public tariff data by the actual railroad-route shipments. Furthermore, the lack of reliable data on county or state-level ethanol demand prevents the use of ethanol consumption as a proxy for actual shipments.
} 
cities contain at least one petroleum fuel terminal or serve as an interchange depot. ${ }^{23}$ Data on the locations of ethanol plants are taken from Ethanol Producer Magazine (2008). The locations of petroleum terminals are taken from the U.S. Environmental Protection Agency (2008). Interchange depots are those identified through conversations with representatives of the Class I railroads.

While some authors such as MacDonald (1989), have expressed reservations about the use of public railroad tariffs, these are the best and most extensive public data on ethanol prices today. Previous studies such as MacDonald (1987), have utilized confidential railroad price and quantity data from the Surface Transportation Board Waybill Sample. Unfortunately, I lack access to these data. Another alternative is the public use file of the Waybill Sample, a subset of the full sample with the confidential data removed. However, these data are unsuitable because they include only a small number of ethanol shipments for a only few routes. ${ }^{24}$ Therefore, despite the limitations, the public tariffs seem the most suitable available data.

\subsection{Geographic data}

Geographic Information Systems (GIS) data on each railroad's rail network were obtained from the Bureau of Transportation Statistics (2007). The data include the physical location of tracks in latitude and longitude coordinates, track length, density of rail traffic on individual track segments, track ownership as well any leases or "trackage rights" provided to other firms. I define a given railroad's network as all segments of track owned by the railroad plus all tracks to which the railroad has trackage rights. ${ }^{25}$

The locations of origin and destination cities were added using latitude and longitude coordinates from the Bureau of Transportation Statistics (BTS). For cities not listed in the BTS rail data, latitude and longitude coordinates were obtained from http://www.batchgeocode.com/. The origin and destination cities for the routes listed in each railroad's public tariffs were checked against that railroad's network. Routes that contain cities that do not appear on the network were dropped

\footnotetext{
${ }^{23}$ Ethanol plants may be operating, idle or under construction. Conversations with railroads indicate that prices may be published some time before a plant begins operation.

${ }^{24}$ For instance, the 2006 sample contains approximately 160 ethanol shipments.

${ }^{25}$ For a given railroad and route, sections of owned track may be separated by sections owned by another railroad but operated through leases or "trackage rights." In practical terms, the inclusion of leased tracks is often necessary for a continuous network. Leases also imply that a given section of track may be part of more than one firm's network. This definition results in network maps that are consistent with route maps published by the various carriers.
} 
from the sample. ${ }^{26}$

The rail distance for each route was calculated as the shortest-distance path between cities on a given carrier's network. The calculation was implemented using the Network Analyst routine in ArcView GIS version 3.3. Figure 2 depicts an example displaying the shortest-distance route between Iowa Falls, IA and West Sacramento, CA on Union Pacific's rail network. Of course, firms may optimize over other factors in addition to distance when selecting a route between origins and destinations. For example, transit time, if congestion or speed limits are a consideration on certain tracks.

To get a sense for the validity of the shortest-distance assumption, the actual routing distances were obtained from the Burlington Northern Santa Fe for approximately 2,200 of the railroad's ethanol routes. ${ }^{27}$ For each route, I calculate the ratio of the shortest-distance path on BNSF's network to BNSF's reported distance. The mean and standard deviation of this ratio for the routes in the ethanol sample are 0.96 and 0.029 , respectively. This suggests that the shortest-distance route is a fair approximation of the actual distance, though on average the calculated distance is slightly smaller.

I obtain GIS data on rail traffic density from the Bureau of Transportation Statistics (2007). The Federal Railroad Administration assigns each section of railroad track to one of seven categories (class $1-7$ ) based on the quantity of freight transported over the track each year. I construct the variable $R T D$ by calculating the mile-weighted average density over the entire route.

Finally, using GIS data from the Bureau of Transportation Statistics (2008), I map ethanol route destinations to $\mathrm{CO}$ non-attainment areas as shown in Figure 3. Of the 151 destinations in the sample, 61 or approximately $40 \%$ are within historical CO non-attainment areas.

\subsection{Summary statistics}

Summary statistics for the combined price and rail mileage data are shown in Table 1. The first column presents statistics for the full sample of price data. The second and third columns summarize

\footnotetext{
${ }^{26}$ One possible explanation is that portions of these routes are served by contract with a regional short-line carrier and therefore are not included in the carrier's network. A second explanation lies in the fact that some sections of track in the BTS rail data are not assigned ownership though they may if fact belong to a Class I carrier.

${ }^{27} \mathrm{BNSF}$ reports distances for the purpose of fuel surcharge calculations at http://www.bnsf.com/bnsf.was6/RailMiles/RMCentralController. Unfortunately, the other railroads in the sample do not report similar data.
} 
the effects of the two types of restrictions imposed on the data. Limiting the sample to observations for which both the origin and destination cities appear on the listing carrier's network reduces the total number of price observations by $27 \%$ from approximately 25,000 to approximately 18,000 as shown in column 2 . The mean price is approximately $2 \%$ higher for the remaining observations after the network restriction is imposed.

Column 3 adds the additional restrictions on origins and destinations requiring that route endpoints contain an ethanol plant, petroleum terminal or serve as a rail interchange. The total sample is reduced by approximately $79 \%$ to approximately 5,200 observations. Compared to the full sample, the mean price and rail mileage of the remaining observations are approximately $7 \%$ and $6 \%$ higher, at $\$ 4,632$ and 1,207 miles respectively. ${ }^{28}$ For individual firms in the sample, the combined effect of these restrictions varies between a 20\% (NS) and 96\% (CSX) reduction in the number of observations. ${ }^{29}$

Summary statistics for variables in the final sample are shown in Table 2. There are 105 origin and 127 destination cities in the final sample. Table 3 summarizes railroad participation at origins and destinations in additional detail. Most routes are highly concentrated with the majority of origins and destinations having only one or two firms. Approximately $94 \%$ of observations have fewer than three railroads participating at either the route origin or destination.

There are four origins and five destinations served by three railroads. Given that these cities make up a small part of the sample, one might be concerned about systematic differences in these markets relative to the rest of the sample. Section 6 demonstrates that the empirical results are robust to exclusion of these cities.

\section{Empirical approach}

The basic empirical model regresses the price per ethanol car shipment on the number of railroads participating at the endpoints of each route. The approach follows studies that estimate a reduced

\footnotetext{
${ }^{28} \mathrm{~A}$ Wald test rejects the equivalence of the base model specification in samples with and without restrictions with an F-statistic of 8.39.

${ }^{29}$ For CSX, the vast majority of observations are dropped due to the origin and destination restrictions. This is because the price data for CSX contain many routes between likely ethanol demand centers, e.g. Washington, DC to Charlotte, NC or from likely demand centers e.g. Buffalo, NY to interchange terminals e.g. Chicago, IL. These types of shipments do not satisfy the origin and destination restricts and seem unlikely to occur frequently in practice.
} 
form model for rail prices. For example see Burton (1993), Schmidt (2001) and Wilson (1994). In this case, the reduced form comes from the demand for transportation, the costs of ethanol rail shipments and market characteristics such as regulation and competition from rail and other freight modes.

Equation 3 shows the main empirical specification. The dependent variable $p_{i j k}$ is railroad $i$ 's price for a single car shipment between origin $j$ and destination $k$. The explanatory variables $N u m_{-} R R_{-}$org $_{j}$ and $N u m_{-} R R_{\_} d e s t_{k}$ represent the number of railroads participating at origin $j$ and destination $k$, respectively. If competition increases with entry, the coefficients $\beta_{5}$ and $\beta_{6}$ are expected to be negative.

I model the relationship between $\mathrm{CO}$ non-attainment status and ethanol prices as a mean effect captured by a zero-one dummy $C O_{-} N A$ that is equal to one if a given destination has ever been designated as a $\mathrm{CO}$ non-attainment area. To differentiate between market power and costs effects of $\mathrm{CO}$ non-attainment status on ethanol rail prices, I interact this dummy with the destination competition variable $N u m_{-} R R_{-}$dest. Under the cost hypothesis, one would expect the coefficient on $C O \_N A$ to be positive but the coefficient on the interaction term, $R R_{-} d e s t \_C O \_N A$, to be zero. This is because cost factors which increase rail prices should be independent of the number of firms participating at each destination. On the other hand, a positive coefficient on $C O \_N A$ and negative and statistically significant coefficient on the interaction term is consistent with market power. This approach is similar to Stavins (2001) though the present approach allows for the endogeneity of the competition variable $n u m \_R R \_d e s t$.

$$
\begin{array}{r}
\log \left(p_{i j k}\right)=\beta_{0}+\beta_{1} \text { Miles }_{i j k}+\beta_{2} \text { Miles }_{i j k} \times \eta_{i}+\beta_{3} M i l e s \_s q_{i j k}+\beta_{4} M i l e s \_s q_{i j k} \times \eta_{i}+ \\
\beta_{5} N u m_{-} R R_{-} \text {rrg }_{j}+\beta_{6} N u m_{-} R R_{-} \text {dest }_{k}+\beta_{7} R R_{-} \text {dest_CO_N } A_{k}+ \\
\beta_{8} C O \_N A_{k}+\beta_{9} R T D_{i j k}+\beta_{10} O \_i n t e r c h a n g e_{j}+ \\
\beta_{11} D \_i n t e r c h a n g e_{k}+\eta_{i}+\eta_{l}+\eta_{m}+\epsilon_{i j k}
\end{array}
$$

Rail costs include route and firm-specific factors. Route-specific cost factors include shipment distance, congestion and terminal costs. Miles $_{i j k}$ is the shortest-distance rail mileage. I model unobserved cost factors that vary at the railroad level, such as productivity and factor prices, as mean effects $\eta_{i}$. Similarly, I incorporate the interaction term $\beta_{2}$ Miles $_{i j k} \times \eta_{i}$ to capture differences 
in the relationship between costs and miles that vary at the railroad level. Because of terminal costs such as loading and switching, the relationship between cost and route distance is likely to be non-linear. Following Burton (1993) I also include the square of the shortest-distance rail mileage Miles_sq $q_{i j k}$ (in units of hundreds of miles squared) and railroad interactions. Because the railroads in the sample each charge a different mileage-based fuel surcharge in addition to the ethanol shipment price, and fuel makes up a substantial portion of shipment cost, I expect significant differences in this relationship across firms. ${ }^{30}$ To account for route congestion I include the weighted-average rail traffic density $R T D$ for each route in the sample. One would expect highly congested routes to have higher costs than less congested routes. Furthermore, if congestion is correlated with railroad participation, failure to account for congestion would bias the estimated effect of competition on prices. ${ }^{31}$ Finally, because terminal costs are likely to be larger for routes ending or beginning at an interchange, O_interchng $g_{j}$ and $D \_i n t e r c h n g_{k}$ are dummy variables that equal one when the origin or destination is an interchange city.

Equation 3 includes destination state fixed effects $\eta_{m}$ to model factors such as environmental policies and automobile use that affect ethanol demand. ${ }^{32}$ Similarly, I model state factors that affect ethanol production, and hence demand for shipping, as mean effects by incorporating origin state fixed effects $\eta_{l} .^{33}$

The main variables that describe market structure are the railroad participation variables Num_RR_org ${ }_{j}$ and Num_RR_dest ${ }_{k}$. Participation is calculated as the number of firms reporting ethanol prices at a given origin or destination. Regulatory factors that vary at the state level are captured by the origin and destination fixed effects. Earlier versions of this paper experimented with variables meant to describe outside options such as barge or truck transport. Results of these models were very similar to those presented in Section 5.

A final issue relates to specification of the dependent variable. Equation 3 regresses log prices on the railroad competition variables and controls. This assumes that the presence of an additional

\footnotetext{
${ }^{30}$ Railroads may assess an additional fuel surcharge to the reported tariff price depending on the type of commodity shipped. Norfolk Southern (NS) does not assess a fuel surcharge to its ethanol shipments. The remaining railroads assessed the following fuel surcharges in April 2008: BNSF ( $\$ 0.54 / \mathrm{mile})$; CN (\$0.207/mile); CSX ( $\$ 0.35 / \mathrm{mile})$; and UP $(\$ 0.26 /$ mile $)$.

${ }^{31}$ If for example entry results in the construction of new tracks that reduce congestion.

${ }^{32}$ Specifications using the total number of vehicles per destination county produce similar results.

${ }^{33}$ For example, corn production, tax incentives for building ethanol plants, cattle feedlots that create markets for ethanol plant bi-products.
} 
competitor has the same percentage impact on prices across routes. Given the substantial variation in prices across routes, this assumption seems reasonable. Results from an estimation using prices in levels as the dependent variable are presented in Section 6.

\subsection{Identification}

A major concern in identifying the effect of competition on the price of ethanol rail shipments is the potential endogeneity of the number of firms participating at the route endpoints. Specifically, one might expect the number of railroads participating at an origin or destination to increase with positive price shocks. ${ }^{34}$ In this case, Num_RR_org and Num_RR_dest would be correlated with the error term and the OLS coefficients on these terms would be biased..$^{35,36}$

To address this issue I instrument for $N u m \_R R \_o r g$ and $N u m \_R R \_d e s t$ using county-level data on agricultural production, manufacturing and population from the 1900 U.S. Census of Population and Housing. Since the total size of the U.S. railroad network peaked in the early 1900's and existing tracks operate on historical right-of-ways, I expect historical rail service to be correlated with present railroad participation. Because I do not observe actual historical railroad participation, I use county-level population, the value of manufactured goods, the value of agricultural crops and the value of livestock production in 1900 as predictors of railroad participation at each origin or destination.

Some authors, notably Deaton (2009), have expressed concern over the use of historical instrumental variables in applications such as this. A valid instrumental variable affects the dependent variable only through its effect on the endogenous regressor, i.e. it is not correlated with the errorterm. Deaton (2009) highlights many examples from the literature where historical instrumental variables are unlikely to satisfy this criterion. In the present application, consistent estimation using instrumental variables requires that the historical instruments affect only railroad participation

\footnotetext{
${ }^{34}$ The bias would run in the opposite direction if merger activity were correlated with unobserved (positive) price shocks. However, efforts of government regulators to maintain pre-existing levels of competition through trackage rights after the merger would minimize this effect. For example, see page 16 of http://www.uprr.com/aboutup/history/decision.pdf

${ }^{35}$ It is difficult to know how readily railroads may enter new geographic markets. On one hand, the large fixed costs of building new tracks poses a significant barrier to entry. However, if trackage rights (leases) are easily negotiated, barriers to entry may be much lower.

${ }^{36}$ The endogeneity problem would not necessarily be alleviated by adopting a fixed-effects specification. Including origin and destination fixed effects may control for unobserved price shocks at the city level. However, route-level shocks could present a similar endogeneity problem.
} 
at route endpoints and not rail prices. Given the long time lag, it seems reasonable to assume that the historical variables are uncorrelated with rail prices in 2008. However, one might imagine the existence of factors such as geography or long-lived policies that cause rail prices today to be correlated with the 1900 census instruments. To control for factors affecting population, manufacturing and agriculture, and in turn rail service that persist over many years, I also include current data on population (U.S. Bureau of Economic Analysis 2005), agricultural production (U.S. Census of Agriculture 2002) and manufacturing (U.S. Census of Manufacturing 2002) as reported in U.S. Census Bureau (2008). The main identifying assumption therefore, is that the differences in these quantities from 1900 to 2008 affect railroad participation but not prices in 2008 .

A second complication arises if ethanol producers also take rail prices into account seeking locations (origins) with negative price shocks. Anecdotal evidence from the siting of recent ethanol plants supports this hypothesis. ${ }^{37}$ Therefore, the method used to select origins, namely requiring that origins be operating ethanol plants, may bias estimates of Equation 3. In many ways this situation is similar to Olley and Pakes (1996) who address the problems of endogeneity and selection due to unobserved productivity in the telecommunications industry. However, here the number of firms participating at the route endpoints may be endogenous and the selection of observations depends on the error term in rail prices.

I account for the possibility of selection bias by adopting a control function approach. ${ }^{38}$ To motivate this choice, consider the following stylized model of the ethanol plant operation decision. Assume that the single period profits of ethanol plant $p$ in period $t$ are given by Equation 4 , where $q_{p, t}$ is the quantity of ethanol produced, $c\left(q_{p, t}\right)$ are variable costs excluding transportation, and $\omega_{p, t}$ represents components of profit not observed by the econometrician. Further assume that the ethanol plant will continue to operate in period $t$ if the present value of future profit streams is positive. This is represented by the Bellman equation shown as Equation 5 .

$$
\begin{gathered}
\pi_{p, t}=p\left(q_{p, t}\right) q_{p, t}-\text { Rail_transport_cost }\left(q_{p, t}\right)-c\left(q_{p, t}\right)+\omega_{p, t} \\
V\left(q_{p, t}, \omega_{p, t}\right)=\max _{q_{p, t}}\left[\pi\left(q_{p, t}, \omega_{p, t}\right)+\beta E V\left(q_{p, t}, \omega_{p, t}\right)\right]>0
\end{gathered}
$$

Assuming that $\omega_{p, t}$ evolves according to a Markov process, I write the ethanol plant's condition to

\footnotetext{
${ }^{37}$ For example, see Zerschling (2008).

${ }^{38}$ Heckman and Hotz (1989) provide an intuitive description of the control function estimator.
} 
continue operations as Equation 6.

$$
p\left(q_{p, t-1}\right) q_{p, t-1}-\text { Rail_transport_cost }\left(q_{p, t-1}\right)-c\left(q_{p, t-1}\right)+\omega_{p, t-1}>0
$$

Rearranging and recognizing that rail transportation costs depend on Equation 3, I rewrite the continuation condition in terms of a function of the base model error, shown as Equation 7 . The unobserved components of ethanol plant profits $\omega_{p, t-1}$ depend in part on $\epsilon_{i j k}$ and in part on factors that I assume are orthogonal to transportation costs. Therefore, to avoid confusion I drop $\omega_{p, t-1}$ from Equation 7.

$$
\begin{array}{r}
p\left(q_{p, t-1}\right) q_{p, t-1}-f\left(\epsilon_{i j k}\right)-c\left(q_{p, t-1}\right)>0 \\
f\left(\epsilon_{i j k}\right)<p\left(q_{p, t-1}\right) q_{p, t-1}-c\left(q_{p, t-1}\right)
\end{array}
$$

The right-hand side of Equation 7 depends on revenue, observable factors of ethanol production and unobserved factors. At the local level, ethanol prices are arguably independent of plant location and therefore should not affect the siting decision. Factors of production in $c\left(q_{p, t-1}\right)$ include corn, energy (electricity, natural gas, coal) and labor plus the co-product animal feed (distiller's dried grains). ${ }^{39}$ I control for corn prices using county-level data on corn production from the 2002 U.S. Census of Agriculture. Energy prices and labor are unlikely to vary substantially by location within a state and therefore should be captured by the origin state fixed-effects. Finally, I control for animal feed prices using county-level livestock production from the 2002 U.S. Census of Agriculture.

A similar selection problem arises if petroleum terminal operators take rail prices into account when establishing facilities for ethanol blending. The petroleum terminal analog to Equation 7 contains cost factors related to gasoline transportation, energy and labor. I control for gasoline transportation cost using the distance between each petroleum blending terminal (destination) and the nearest petroleum refinery as reported by the U.S. Environmental Protection Agency (2008). Energy prices and labor are captured by the destination state fixed-effects.

\subsection{Clustering}

A final issue relates to the standard errors of the estimated coefficients. As mentioned previously, several of the railroads in the sample group origins and destinations into price groups. For observations in the same price-group, the disturbance terms are likely correlated. One might also

\footnotetext{
${ }^{39}$ For an engineering analysis, see Kwiatkowski et al. (2006).
} 
expect origin or destination-level common shocks for origins and destinations that are not part of price groups because of unobservables that vary at the city level. Because both route origins and destinations may be affected, I cluster on origin price-group and destination price-group. ${ }^{40}$ Cities not reported as part of a price group are assigned to their own group for the purpose of calculating cluster-robust standard errors. ${ }^{41}$ It is important to note that clustering on origin and destination price groups assigns observations to clusters based on each railroad's price group structure. Cluster robust standard errors calculated in this manner do not account for city-level shocks that are common across railroads. Differences in each firm's price group structure prevent clustering on both the price group and city levels. Standards errors clustered at the origin and destination city-level are qualitatively similar to those reported in Section 5 .

\section{$5 \quad$ Results}

Results from estimation of Equation 1 are shown in Tables 4 and 5. The first-stage regression results are presented in Table 4. In the origin first-stage, the agricultural and population instruments are statistically significant $(p<0.01)$. The value of historical manufacturing output is negative and not statistically significant. In the destination first-stage, the manufacturing, livestock and population instruments are statistically significant $(p<0.01)$. The coefficient on historical crop production is positive and not statistically significant. For destinations in non-attainment areas population, manufacturing and agricultural production are statistically significant. The missing standard errors represent negative entries on the diagonal of the two-way cluster robust variance covariance matrix. Cameron, Gelbach and Miller (2009) describe circumstances when this may occur. A F-test for the joint significance of the instruments rejects the null hypothesis that the instruments have no significance in predicting railroad participation with F-statistics of $61.91,1211.29$ and 108.22 for the origin, destination and non-attainment destination interaction terms, respectively.

The estimates of the main parameters of interest are presented in Table 5. The origin and destination state fixed-effects as well as the census variables have been suppressed to simplify the presentation of results. Column 1 shows OLS estimates of the full sample. Because historical data used to construct the instrumental variables are not available for the entire sample, the total

\footnotetext{
${ }^{40}$ I employ the "multi-way" algorithm described by Cameron, Gelbach and Miller (2010) to calculate "2-way" cluster-robust standard errors, clustering on origin and destination group.

${ }^{41}$ Clustering on route produces similar standard errors.
} 
number of observations used in the 2SLS estimation is reduced. Column 3 reports OLS estimates using the reduced sample. Column 5 presents the 2 SLS estimates. ${ }^{42,43}$

The estimated coefficients on the railroad fixed-effects, distance terms and their interactions are in general statistically significant and similar in magnitude across the three models. The smaller sample used in the 2SLS model results in somewhat larger point estimates for the CO non-attainment effects, relative to OLS in the full sample. However as the results are qualitatively similar across models, I will focus my discussion on the 2SLS estimates in column 5.

Evaluated at the mean prices and distances, an additional mile increases the price of an ethanol shipment between $\$ 1.24$ and $\$ 3.12$ per car depending on the railroad. This translates to between 1.3 and 3.2 cents per ton-mile. Published mileage scales for BNSF and UP list the price per mile of an ethanol shipment at $\$ 1.47$ to $\$ 2.43$ per mile or 1.5 to 2.5 cents per ton-mile. Column 5 implies values of 1.3 and 1.5 cents per ton-mile for BNSF and UP, respectively. The coefficients on the interchange dummies are positive and significant suggesting that prices for routes with a destination or origin interchange are higher (3.1\% to $5.0 \%)$ compared to other routes.

An increase in average density $R T D$ of one class is correlated with a decrease in price of approximately 1\%. It is well known that railroads exhibit economies of density. For example see Ivaldi and McCollough (2001). Therefore, the negative coefficient on average density is not surprising. However, one might still expect congestion on routes with very high density resulting in slower travel speeds and higher costs. Therefore, the combined effect on prices may be positive, negative or u-shaped. In unreported results I allow the effect of $R T D$ to be nonlinear by grouping the route average rail traffic density into seven dummy variables. These results do show the $\mathrm{u}-$ shaped effect of density with a minimum at an average rail traffic density of six. However, the estimated coefficients on num_RR_org and num_RR_dest are quite similar to those reported in Table 5 .

Increased competition leads to lower prices for ethanol shipments. For each additional railroad participating at the route origin, price decreases by approximately $3.4 \%$, on average. The effect of an additional railroad at the destinations not is $\mathrm{CO}$ non-attainment areas is negative, but small

\footnotetext{
${ }^{42}$ As a check I also estimate the instrumental variable specification using the generalized method of moments. The results are very similar to the estimates presented in Table 5.

${ }^{43}$ Both the 2SLS and GMM estimates use the "ivreg2" module written by Baum, Schaffer and Stillman (2007).
} 
and not statistically significant. These results are robust across the three models summarized in Table 4 though the effect at the route origin is over twice as large in the 2SLS estimates.

Prices for destinations in non-attainment areas are higher than prices for other destinations. The magnitude of the price difference decreases as the number of railroads participating at the destination increases. The coefficient on the dummy for CO non-attainment status is positive and significant $(p<0.01)$ while the coefficient on the interaction term is negative and significant with $(p<0.01) .{ }^{44}$ Focusing on the 2SLS estimates in the third column of Table 5, monopolist prices are approximately $3.1 \%$ higher on average in $\mathrm{CO}$ non-attainment areas compared to other destinations. For each additional entrant, the price premium falls by $2.3 \%$. These results are consistent with railroads practicing price discrimination based on environmental regulations at the route destination.

A concern one may have in interpreting these results is whether $\mathrm{CO}$ non-attainment areas are different from other destinations in ways not captured by the model. Positive price (or cost) shocks or omitted variables that are correlated with non-attainment designation could explain the results in Table 5. To further investigate this issue, I conduct a simple falsification exercise using the Surface Transportation Board Public Waybill Sample (2007). The Waybill Sample contains rail price (revenue), distance, origin and destination data for approximately 600,000 shipments of several hundred different commodities. In the public sample, origins and destination cities are aggregated and reported by BEA economic area. I regress the price per rail shipment on shipment miles, miles squared, the number or railroads who operate tracks in a given origin or destination area, commodity fixed effects, and a dummy that is equal to one if the destination area contains at least one CO non-attainment area. The estimated coefficient on the non-attainment dummy is negative (-14.65) and is not statistically significant at standard testing levels. This suggests that rail prices for shipments of commodities other than ethanol to non-attainment areas are no higher than for other destinations. This result lends further support to the price discrimination interpretation of the results presented in Table 5.

\footnotetext{
${ }^{44}$ Results using only destinations that were once non-attainment but have since come into attainment are qualitatively similar. This suggests that some aspect of non-attainment designation which impacts ethanol demand persists after the designation has been lifted.
} 


\section{Robustness checks}

In this section I describe a number of robustness checks related to the possibility of model misspecification in estimating Equation 3. Specifically, Table 6 presents results using alternate controls for route congestion, omitting destinations served by three railroads, defining competition at the route level, and using price in levels as the dependent variable. Column 1 of Table 6 presents estimates from the preferred specification for comparison.

Given that CO non-attainment status is likely to increase ethanol shipments to these destinations, one might be particularly concerned about the role capacity constraints (congestion) may play in the observed prices. Higher prices would be expected if non-attainment increased shipments to a level near the capacity constraint. Likewise, prices would be expected to decrease with entry if entrants utilize new rail lines (or terminals) thus easing congestion. Furthermore, route-level rail traffic density may not adequately control for these effects at route destinations. To address these issues I replace the route weighted-average rail traffic density $R T D$ with Org_density and Dest_density, the rail traffic density at the origin and destination, respectively. This specification isolates the effects of capacity constraints at the route endpoints.

The second column of Table 6 presents results using the origin and destination rail traffic density measures. The coefficients on rail traffic density at the route endpoints are both positive, though the origin effect is not statistically significant. At the destination, an increase in rail traffic density class is correlated with a price increase of approximately $0.4 \%$. The coefficients on the railroad participation variables, $\mathrm{CO}$ non-attainment status and the interaction term are comparable to those presented in column $1 .{ }^{45}$ Taken together, these results suggest that the observed price behavior at destinations in $\mathrm{CO}$ non-attainment areas is not the result of railroad capacity constraints.

As shown in Table 1, approximately $4 \%$ to $6 \%$ of observations are served by three railroad at either the route origin or destination. Furthermore, these observations represent a small number of cities. To the extent the the price effects captured by the linear railroad participation variables are driven by cities with three railroads, one may worry about the potential influence of unobserved characteristics in these markets. Column 3 of Table 6 presents results excluding all cities with three or more railroads. The competition variables therefore measure the effects of moving from monopoly

\footnotetext{
${ }^{45}$ Including the route-level average density $R T D$ in addition to the endpoint densities produces very similar results.
} 
to duopoly in rail transportation. At the origin, the effect on prices of adding an additional railroad is negative, though slightly smaller in magnitude than in the full sample and significant at the $10 \%$ level. The effects in CO non-attainment areas are consistent with the full sample estimates, though larger in magnitude. The coefficient on the interaction term is less precisely estimated than in the full sample, though still statistically significant at the $10 \%$ level.

If the appropriate measure of competition is at the route level as opposed to at route endpoints, the base model may be misspecified. Column 4 present results of a model where the origin and destination participation variables are replaced with the route equivalent. I instrument for Num_RR_route with the same instruments used to identify $N u m_{-} R R_{-}$org and Num_RR_dest. The indicator variable for non-attainment status is the same as in the base model. The interaction term $R R_{-}$route_CO_NA is the interaction of the non-attainment dummy and the number of railroads on a give route. The parameters of interest are qualitatively consistent with base model. The effect of adding an additional railroad to a route whose destination is not in a non-attainment area is negative, though not statistically significant. The coefficients on non-attainment status and the interaction term are larger than in the base model, though not precisely estimated. These results bolster the base model results and support the notion that the relevant measures of competition are at the route origins and destinations.

Finally, the fifth column of Table 6 presents results with shipment prices specified in levels. For the average route in the sample, these results are qualitatively similar to the base model. Evaluated at mean prices, the effect of adding an additional railroad at the route origin decreases shipment prices by approximately $3.3 \%$ on average. Monopolist prices in non-attainment areas are on average $\$ 148$ or $3.8 \%$ higher. This price premium falls by $\$ 101$ or approximately $2.6 \%$ with each additional entrant.

\section{Conclusions}

The goal of this paper is to investigate whether railroads exercise market power in the transportation of fuel ethanol. Historically, ethanol demand in the U.S. has been driven by state and federal policies. New policies such as the RFS seek to dramatically expand the use of ethanol. Understanding the effect of market power provides valuable information for the evaluation of these policies. Evidence of market power could change the regulatory choices of policymakers. 
I find compelling evidence that railroads do exercise market power in the transportation of ethanol. The data show that prices depend on the level of competition at route origins and destinations. Firms are able to price discriminate based on environmental regulations at the route destinations. Specifically, prices for ethanol delivered to cities within CO non-attainment areas are significantly higher than prices for other destinations. The price difference decreases for more competitive destinations.

There are several implications of these findings that pertain to new ethanol policies such as renewable fuel standards or low carbon fuel standards. First, because rail carriers are able to exercise market power, policies that promote ethanol may incur additional social costs. To the extent that ethanol policies are aimed at increasing welfare, the effect of market power on prices and consumption must be considered. Second, the new policies themselves may cause prices to vary across routes, all else equal. For example, the data presented here suggest that CO non-attainment designation allows firms in concentrated markets to raise prices at the expense of customers whose demand for ethanol is inelastic. This suggests a rather perverse effect that regulations designed to improve environmental quality may actually make abatement more costly by increasing the price of a clean input. New policies may enable similar price discrimination. Third, prices are reduced substantially in markets with even a small number of competitors. Policies that minimize exposure to highly concentrated rail transportation markets can help mitigate the effects of market power.

Finally, while quantifying the effects of price discrimination in terms of prices is an important first step, evaluating the full welfare costs of environmental regulations requires a more detailed look at demand and market structure. A structural econometric approach that allows for the evaluation of consumer and producer welfare with and without regulation is an important area for future research. 


\section{References}

[1] Anderson, Soren T. 2010. "The Demand for Ethanol as a Gasoline Substitute." NBER working paper \#16371.

[2] Association of American Railroads. 2008a. "Class I Railroad Statistics." Policy and Economics Department. http://www.aar.org/ /media/AAR/Industry\%20Info/Statistics.ashx, accessed August 1, 2008.

[3] Association of American Railroads. 2008b. "Railroads and Ethanol." Policy and Economics Department. http://www.aar.org/IndustryInformation/ /media/AAR/BackgroundPapers/ Railroads\%20and\%20Ethanol.ashx, accessed August 1, 2008.

[4] Baum, C.F., Schaffer, M.E., Stillman, S. 2007. ivreg2: Stata module for extended instrumental variables/2SLS, GMM and $A C / H A C, L I M L$ and $k$-class regression. http://ideas.repec.org/c/boc/bocode/s425401.html

[5] Berry, Steven T. 1992. "Estimation of a model of entry in the airline industry." Econometrica, 60(4): 889-917.

[6] Berry, Steven T. and Peter Reiss. 2007. "Empirical Models of Entry and Market Structure." Handbook of Industrial Organization, Volume 3, Chapter 29.

[7] Borenstein, Severin. 1991. "Selling Costs and Switching Costs: Explaining Retail Gasoline Margins." The RAND Journal of Economics, 22(3): 354-369.

[8] Borenstein, Severin and Nancy Rose. 1994. "Competition and Price Dispersion in the U.S. Airline Industry." The Journal of Political Economy, 102(4): 653-683.

[9] Boyer, Kenneth D. 1987. "The Costs of Price Regulation: Lessons from Railroad Deregulation." The RAND Journal of Economics, 18(3): 408-416.

[10] Bresnahan, Timothy and Peter Reiss. 1991. "Entry and Competition in Concentrated Markets." Journal of Political Economy, 99(5): 977-1009.

[11] Burlington Northern Santa Fe Railway. 2008. "April 2008 Ethanol Rate Adjustment." http://www.bnsf.com/markets/agricultural/ag_news/year2008/pricing08/p03-06-08a.html, accessed April 28, 2008. 
[12] Burton, Mark L. 1993. "Railroad Deregulation, Carrier Behavior, and Shipper Response: A Disaggregated Analysis." Journal of Regulatory Economics, 5: 417-434.

[13] Busse, Meghan R. and Nathaniel O. Keohane. 2007. "Market Effects of Environmental Regulation: Coal, Railroads, and the 1990 Clean Air Act." The RAND Journal of Economics, Winter 2007, 38(4): 1159-1179.

[14] Cameron, Colin A., Johan B. Gelbach and Douglas L. Miller. 2010. "Robust inference with Multi-Way Clustering." Journal of Business and Economic Statistics, forthcoming.

[15] Canadian National. 2008. "Price Documents." http://www.cn.ca/customer_centre/shipping_tools /prices_services/price_docs/en_tool_prices_pricedocs.shtml, accessed April 18, 2008.

[16] Chevalier, Judith and Austan Goolsbee. 2003. "Measuring Prices and Price Competition Online: Amazon.com and BarnesandNoble.com." Quantitative Marketing and Economics, 1: 203222.

[17] CSX Corporation. 2008. "Full Text Price Lists." http://www.csx.com/?fuseaction=customers. pricing_lists, accessed April 23, 2008.

[18] Deaton, Angus S. 2009. "Instruments of Development: Randomization in the Tropics, and the Search for the Elusive Keys to Economic Development." NBER Working Paper \#w14690.

[19] Ellig, Jerry. 2002. "Railroad Deregulation and Consumer Welfare." Journal of Regulatory Economics, 21(2): 143-167.

[20] Ethanol Producer Magazine. 2008. "Plant List and Online Plant Map." Ethanol Producer Magazine. http://www.ethanolproducer.com/plant-list.jsp?country=USA\&view=, accessed June $3,2008$.

[21] Farrell, Alex E., Richard J. Plevin, Brian T. Turner, Andrew D. Jones, Michael O'Hare, and Daniel M. Kammen. 2006. "Ethanol Can Contribute to Energy and Environmental Goals." Science, 311(5760): 506-508.

[22] Friedlaender, Ann F. 1992. "Coal Rates and Revenue Adequacy in a Quasi-Regulated Industry." The RAND Journal of Economics, 23(3): 376-394. 
[23] Heckman, James J. and V. Joseph Hotz. 1989. "Choosing Among Alternative Nonexperimental Methods for Estimating the Impact of Social Programs: The Case of Manpower Training." Journal of the American Statistical Association, 84(408): 862-874.

[24] Holland, Stephen P., Jonathan E. Hughes and Christopher R. Knittel. 2009. "Greenhouse Gas Reductions under Low Carbon Fuel Standards?" American Economic Journal: Economic Policy, 1(1): 106-146.

[25] Hughes, Jonathan E., Christopher R. Knittel, and Daniel Sperling. 2008. "Evidence of a Shift in the Short-Run Price Elasticity of Gasoline Demand." Energy Journal, 29(1): 113-134.

[26] Ivaldi, M. and G. J. McCullough. 2001. "Density and Integration Effects on Class I U.S. Freight Railroads." Journal of Regulatory Economics, 19(2): 161-182.

[27] Kunce, M., S. Hamilton, and S. Gerking. 2005. "Marketable Permits, Low-Sulfur Coal and the Behavior of Railroads." Mimeo, University of Wyoming.

[28] Kwiatkowski, Jason R., Andrew J. McAloon, Frank Taylor and David B. Johnston. 2006. "Modeling the Process and Costs of Fuel Ethanol Production by the Corn Dry-Grind Process." Industrial Crops and Products, 23: 288-296.

[29] MacDonald, James M. 1987. "Competition and Rail Rates for the Shipment of Corn, Soybeans, and Wheat." The RAND Journal of Economics, 18(1): 151-163.

[30] MacDonald, James M. 1989. "Railroad Deregulation, Innovation, and Competition: Effects of the Staggers Act on Grain Transportation." Journal of Law and Economics, 32(1): 63-95.

[31] McAloon, Andrew, Frank Taylor and Winnie Yee. 2000. "Determining the Cost of Producing Ethanol from Corn Starch and Lignocellulosic Feedstocks." National Renewable Energy Laboratory report NREL/TP-580-28893, October 2000.

[32] McFarland, Henry. 1989. "The Effects of United States Railroad Deregulation on Shippers, Labor and Capital." Journal of Regulatory Economics, 1: 259-270.

[33] McNew, Kevin, and Duanne Griffith. 2005. "Measuring the Impact of Ethanol Plants on Local Grain Prices." Review of Agricultural Economics, 27(2): 164-180. 
[34] Norfolk Southern Corporation. 2008. "Public Price Publications." http://www.nscorp.com/mktgpublic/publicprices, accessed April 17, 2008.

[35] Olley, Steven and Ariel Pakes. 1996. "The Dynamics of Productivity in the Telecommunications Equipment Industry." Econometrica, 64(6): 1263-1297.

[36] Rask, Kevin N. 1998. "Clean Air and Renewable Fuels: The Market for Fuel Ethanol in the U.S. from 1984 - 1993." Energy Economics, 20: 325-345.

[37] Renewable Fuels Association. 2010. "Industry Statistics." http://www.ethanolrfa.org/pages/statistics/, accessed November 24, 2010.

[38] Schmidt, Stephen. 2001. "Market Structure and Market Outcomes in Deregulated Freight Rail Markets." International Journal of Industrial Organization, 19: 99-131.

[39] Searchinger, Timothy, et.al. 2008. "Use of U.S. Croplands for Biofuels Increases Greenhouse Gases Through Emissions From Land-Use Change." Science, 319: 1238-1240.

[40] Shepard, Andrea. 1991. "Price Discrimination and Retail Configuration." The Journal of Political Economy, 99(4): 30-53.

[41] Stavins, Joanna. 2001. "Price Discrimination in the Airline Market: The Effect of Market Concentration." The Review of Economics and Statistics, 83(1): 200-202.

[42] Union Pacific Railroad. 2008. "Price and Transit Time Inquiry." http://c02.my.uprr.com/cdm/pricedocument/price_document.jas, accessed April 17, 2008.

[43] U.S. Bureau of Transportation Statistics. 2007. "National Transportation Atlas Database 2007." U.S. Department of Transportation. http://www.bts.gov/publications/national_transportation_atlas_database/2007/, accessed May 15, 2008.

[44] U.S. Census Bureau. 2008. "1900 U.S. Census of Population and Housing." U.S. Census Bureau. http://www.census.gov/prod/www/abs/decennial/1900.htm, accessed June 30, 2008.

[45] U.S. Census Bureau. 2008. "USA Counties Data Files." U.S. Census Bureau. http://www.census.gov/support/DataDownload.htm, accessed June 30, 2008. 
[46] U.S. Congress. 2007. "Energy Independence and Security Act of 2007: H.R.6." U.S. Library of Congress. http://thomas.loc.gov/cgi-bin/bdquery/z?d110:h.r.00006:, accessed August 1, 2008.

[47] U.S. Department of Energy. 2008. "Alternative Fuels and Advanced Vehicles Data Center, E85 Fueling Station Locations." Energy Efficiency and Renewable Energy. http://www.eere.energy.gov/afdc/ethanol/ethanol_locations.html, accessed August 21, 2008.

[48] U.S. Department of Energy. 2008. "Oxygenate Production." Energy Information Administration. http://tonto.eia.doe.gov/dnav/pet/pet_pnp_oxy_dc_nus_mbbl_a.htm, accessed August 1, 2008.

[49] U.S. Environmental Protection Agency. 2008. "Locational Data Improvement Project." Envirofacts database. http://www.epa.gov/enviro/html/locational/, accessed May 16, 2008.

[50] U.S. Environmental Protection Agency. 2007. "Reformulated Gasoline Where You Live." http://www.epa.gov/otaq/rfg/whereyoulive.htm, accessed August 1, 2008.

[51] U.S. Environmental Protection Agency. 2005. "State Winter Oxygenated Fuel Program Requirements for Attainment of Maintenace of CO NAAQS." EPA420-B-05-113, November 2005.

[52] Wilson, Wesley W. 1994. "Market-Specific Effects of Rail Deregulation." The Journal of Industrial Economics, 42(1): 1-22.

[53] Zerschling, Lynn. 2008. "Railroad official knew ethanol plant would overload tracks." Sioux City Journal. http://www.siouxcityjournal.com/articles/2006/03/18/news/local/ caaa51a008aad434862571350017961f.txt, accessed on August 29, 2008. 
Figure 1: Locations of ethanol plants and shipment destinations

\section{Ethanol Plant Locations and Railroad Destinations}

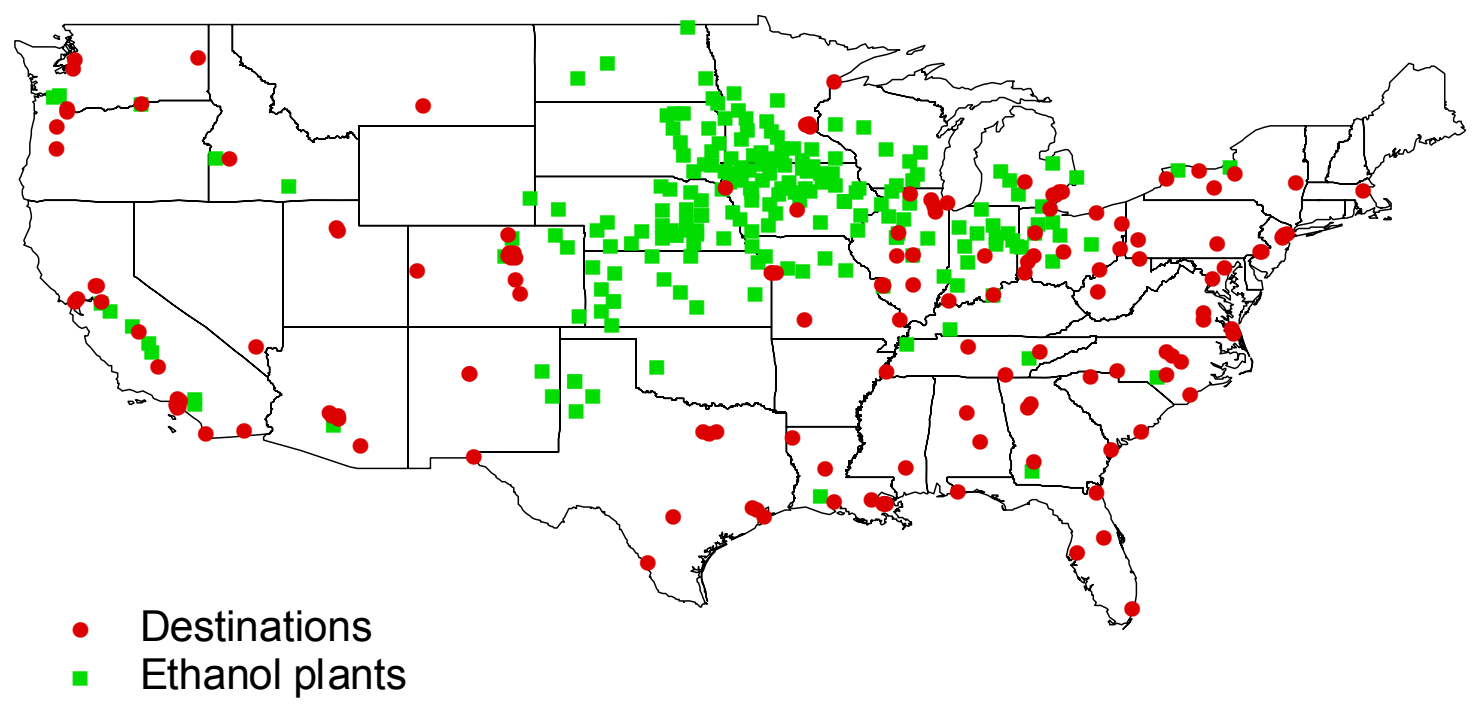


Figure 2: Shortest distance route from Iowa Falls, IA to West Sacramento, CA on Union Pacific's rail network

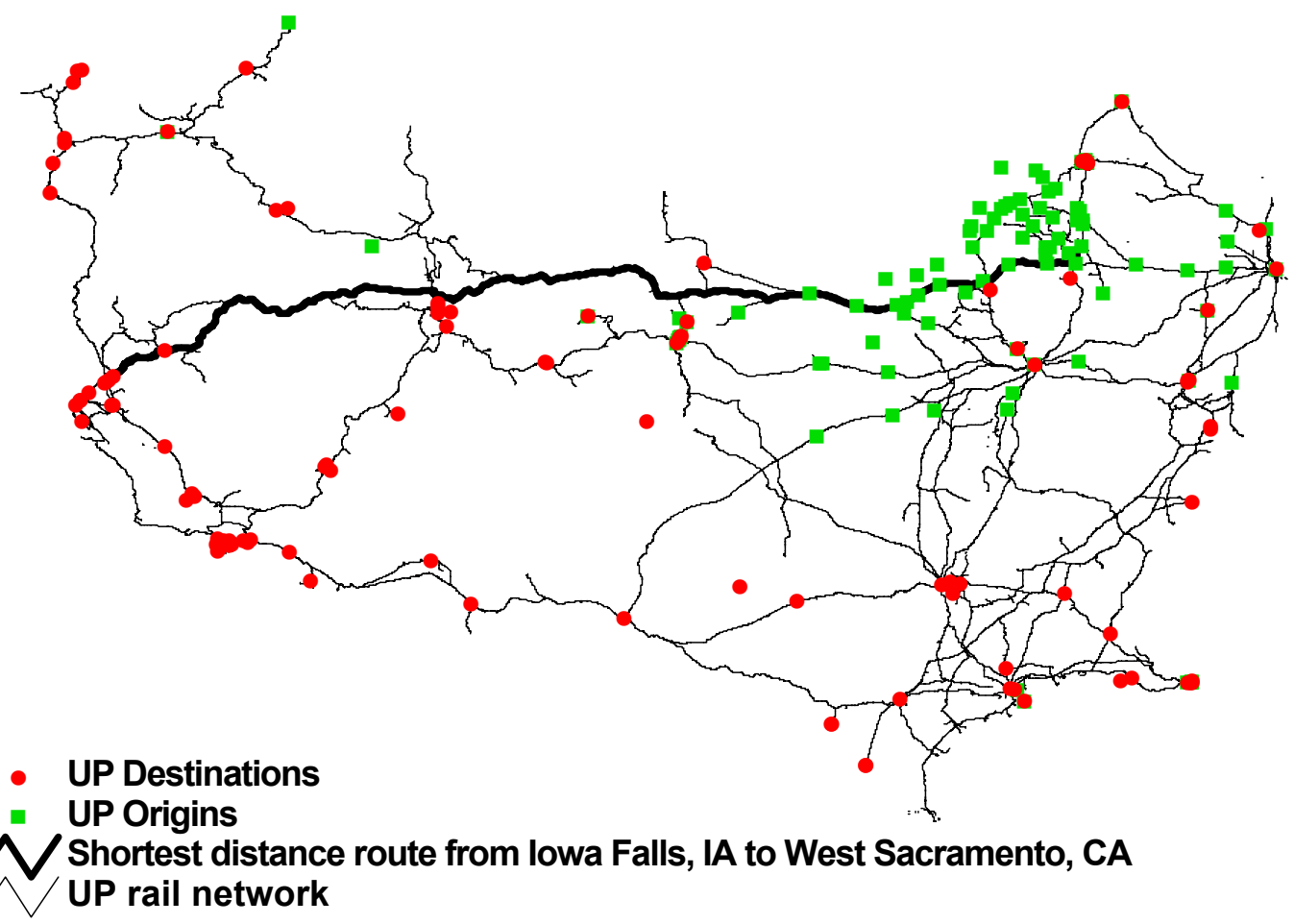


Figure 3: CO non-attainment areas and ethanol destinations

\section{CO Non-Attainment Areas and Railroad Destinations}

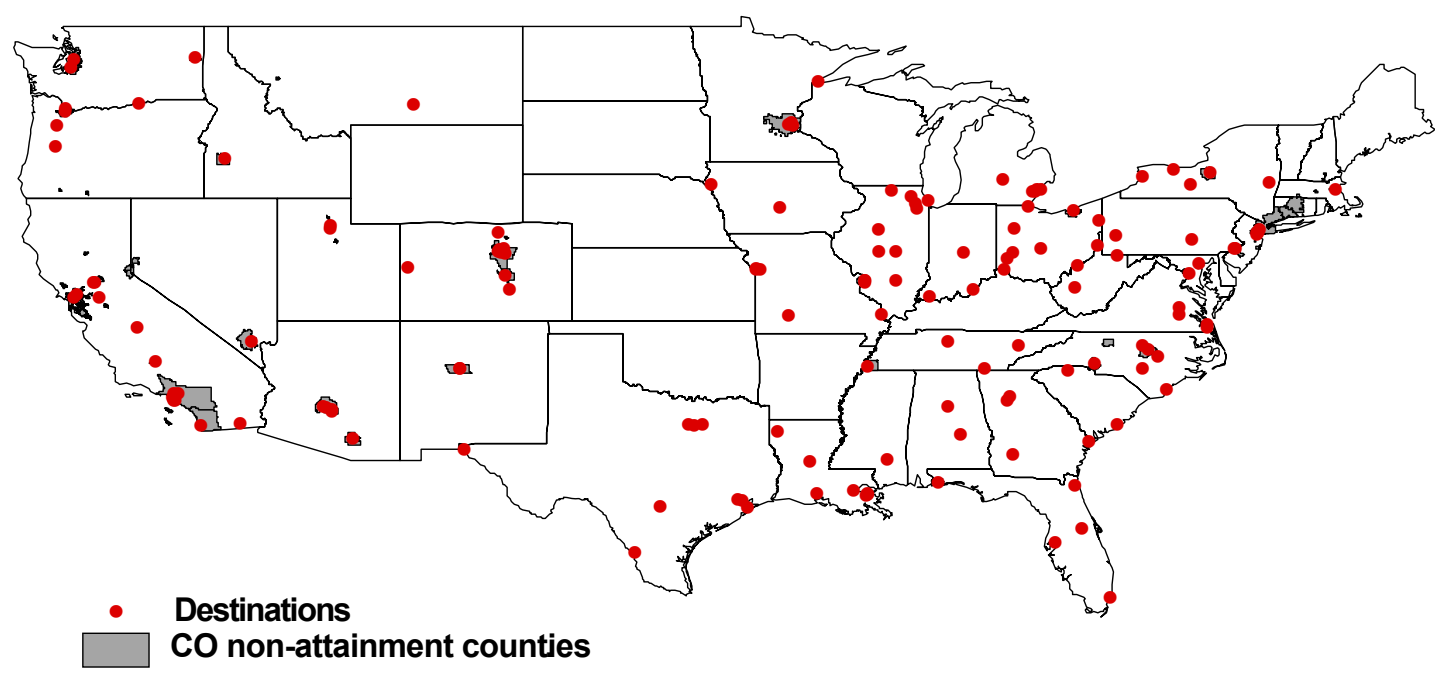


Table 1: Summary statistics for sample restrictions

\begin{tabular}{rrrrr} 
& & Full Sample & On Rail Network & Final Sample \\
\hline \hline Num. Obs. & & & \\
& BNSF & 11,280 & 8,059 & 2,597 \\
& CN & 76 & 58 & 36 \\
& CPR & 4 & 4 & 4 \\
& CSX & 7,224 & 4,828 & 318 \\
& KCS & 20 & 20 & 8 \\
& NS & 86 & 84 & 69 \\
& UP & 6,432 & 5,266 & 2,145 \\
\hline \multicolumn{2}{c}{ Total Obs. } & 25,122 & 18,319 & 5,177 \\
\hline \hline Price & & & \\
& num. obs. & 25,098 & 18,295 & 5,165 \\
& mean & $\$ 4,336.06$ & $\$ 4,415.23$ & $\$ 4,631.87$ \\
& std. dev. & $\$ 1,219.52$ & $\$ 1,227.70$ & $\$ 1,130.96$ \\
& min & $\$ 803.00$ & $\$ 803.00$ & $\$ 816.00$ \\
& max & $\$ 7,206.00$ & $\$ 7,070.00$ & $\$ 7,025.00$ \\
\hline Miles & & & & \\
& num. obs. & 18,401 & 18,319 & 5,177 \\
& mean & 1139.4 & 1144.5 & 1207.2 \\
& std. dev. & 592.7 & 589.1 & 597.4 \\
& min & 0.0 & 1.5 & 3.6 \\
& max & 2670.5 & 2670.5 & 2670.5 \\
\hline \hline
\end{tabular}

Notes: Price data not available for CPR and KCS 
Table 2: Summary statistics

\begin{tabular}{|c|c|c|c|c|c|}
\hline Variable & Description & Mean & Std. Dev. & Min. & Max. \\
\hline Price & Shipment price (\$) & 4,632 & 1,131 & 816 & 7,025 \\
\hline Miles & Shortest-distance route miles & 1,208 & 597 & 4 & 2,671 \\
\hline Miles_sq & Shortest-distance route miles squared & $1,817,149$ & $1,490,376$ & 13 & $7,131,576$ \\
\hline Num_RR_org & Number of firms participating at route origin & 1.3 & 0.6 & 1.0 & 3.0 \\
\hline Num_RR_dest & Number of firms participating at route destination & 1.7 & 0.9 & 1.0 & 6.0 \\
\hline O_interchng & Dummy $=1$ if origin is an interchange & 0.1 & 0.4 & 0.0 & 1.0 \\
\hline D_interchng & Dummy $=1$ if destination is an interchange & 0.1 & 0.3 & 0.0 & 1.0 \\
\hline Num $R R$ route & Number of firms participating on route & 1.1 & 0.3 & 1.0 & 2.0 \\
\hline RTD & Density of rail freight traffic (class 1-7) & 4.8 & 0.8 & 1.0 & 6.9 \\
\hline CO_NA & Dummy $=1$ if destination is $\mathrm{CO}$ non-attainment area & 0.6 & 0.5 & 0.0 & 1.0 \\
\hline O_pop_1900 & Origin population in 1900 (million) & 0.1 & 0.3 & 0.0 & 1.8 \\
\hline O_vcrops_1900 & Origin value of crops produced in 1900 (\$ millions) & 49.3 & 30.7 & 0.4 & 195.3 \\
\hline O vlstk 1900 & Origin value of livestock in 1900 (\$ millions) & 41.1 & 21.0 & 7.1 & 117.0 \\
\hline O_vman_1900 & Origin value of manufactured goods in 1900 (\$ millions) & 626.2 & $3,007.8$ & 0.0 & $20,044.5$ \\
\hline O_corn 2002 & Origin total corn production in 2002 (million bu) & 14.8 & 11.0 & 0.0 & 45.7 \\
\hline O_pop_2000 & Origin population in 2000 (millions) & 0.3 & 0.9 & 0.0 & 5.3 \\
\hline O_vcrops_2002 & Origin value of crops produced in 2002 (\$ millions) & 72.3 & 46.0 & 0.0 & 238.9 \\
\hline O vlstk 2002 & Origin value of livestock in 2002 ( $\$$ millions) & 104.7 & 175.5 & 0.0 & $1,076.4$ \\
\hline O_vman_2002 & Origin value of manufactured goods in 2002 (\$ millions) & $4,636.3$ & $14,385.0$ & 0.0 & $78,208.3$ \\
\hline D_pop_1900 & Destination population in 1900 (millions) & 0.1 & 0.3 & 0.0 & 1.8 \\
\hline D_vcrops_1900 & Destination value of crops produced in 1900 (\$ millions) & 65.2 & 49.7 & 2.4 & 185.0 \\
\hline D_vlstk_1900 & Destination value of livestock in 1900 ( $\$$ millions) & 35.5 & 19.1 & 0.0 & 87.8 \\
\hline D_vman_1900 & Destination value of manufactured goods in 1900 ( $\$$ millions) & $1,024.9$ & $3,233.6$ & 2.6 & $20,044.5$ \\
\hline D_refinery_dist & Destination distance to nearest petroleum refinery (miles) & 19.8 & 31.7 & 0.3 & 194.2 \\
\hline D pop 2000 & Destination population in 2000 (millions) & 0.8 & 1.5 & 0.0 & 5.3 \\
\hline D_vcrops_2002 & Destination value of crops produced in 2002 (\$ millions) & 83.0 & 63.1 & 0.0 & 389.2 \\
\hline D_vlstk_2002 & Destination value of livestock in 2002 ( $\$$ millions) & 66.2 & 118.1 & 0.0 & $1,076.4$ \\
\hline D_vman_2002 & Destination value of manufactured goods in 2002 (\$ millions) & $13,679.2$ & $26,625.8$ & 0.0 & $78,208.3$ \\
\hline
\end{tabular}


Table 3: Railroad participation at route endpoints

\begin{tabular}{|c|c|c|}
\hline & $\begin{array}{l}\text { Number of Origins } \\
\text { or Destinations }\end{array}$ & $\begin{array}{l}\text { Percent of Total } \\
\text { Observations }\end{array}$ \\
\hline \multicolumn{3}{|l|}{ Origins } \\
\hline One RR & 3814 & $73.8 \%$ \\
\hline Two RR & 1064 & $20.6 \%$ \\
\hline Three RR & 287 & $5.6 \%$ \\
\hline Four RR & 0 & $0.0 \%$ \\
\hline Five RR & 0 & $0.0 \%$ \\
\hline Six RR & 0 & $0.0 \%$ \\
\hline \multicolumn{3}{|l|}{ Destination } \\
\hline One RR & 2316 & $44.8 \%$ \\
\hline Two RR & 2546 & $49.3 \%$ \\
\hline Three RR & 185 & $3.6 \%$ \\
\hline Four RR & 0 & $0.0 \%$ \\
\hline Five RR & 0 & $0.0 \%$ \\
\hline Six RR & 118 & $2.3 \%$ \\
\hline
\end{tabular}


Table 4: First-stage - Railroad participation at route origins and destinations

Table 1: First Stage - 2SLS

\begin{tabular}{|c|c|c|c|c|c|c|}
\hline & \multicolumn{2}{|l|}{ Origin } & \multirow{2}{*}{$\begin{array}{c}\text { Dest. } \\
0.0971\end{array}$} & \multicolumn{3}{|c|}{ Dest. CO NA } \\
\hline O_pop_1900 & $3.451^{* * *}$ & $(0.652)$ & & $(0.214)$ & 0.208 & $()$. \\
\hline O_vcrops_1900 & $-5.674^{* * *}$ & $(1.341)$ & 0.661 & $(0.522)$ & -0.169 & $(0.353)$ \\
\hline O_vlstk_1900 & $9.241^{* * *}$ & $(1.351)$ & -0.503 & $(0.577)$ & -0.000665 & $(0.368)$ \\
\hline O_vman_1900 & -0.0596 & $(0.0772)$ & -0.0279 & $(0.0206)$ & -0.00768 & $()$. \\
\hline D_pop_1900 & -0.0772 & $(0.198)$ & $-2.087^{* * *}$ & $(0.306)$ & $-4.064^{* * *}$ & $(0.263)$ \\
\hline D_vcrops_1900 & 0.104 & $(0.267)$ & 0.327 & $(0.399)$ & $3.087^{* * *}$ & $(0.371)$ \\
\hline D_vlstk_1900 & -0.0995 & $(0.319)$ & $3.984^{* * *}$ & $(0.578)$ & $3.780^{* * *}$ & $(0.419)$ \\
\hline D_vman_1900 & 0.00621 & $(0.0169)$ & $0.431^{* * *}$ & $(0.0264)$ & $0.350^{* * *}$ & $(0.0223)$ \\
\hline O_pop_2005 & $-2.269^{* * *}$ & $(0.428)$ & 0.221 & $(0.141)$ & -0.0990 & $(0.0851)$ \\
\hline O_vcrops_2002 & $2.717^{* * *}$ & $(0.658)$ & -0.259 & $(0.358)$ & 0.126 & $(0.260)$ \\
\hline O_vlstk_2002 & -0.224 & $(0.146)$ & 0.0371 & $(0.0775)$ & -0.0415 & $(0.0507)$ \\
\hline O_vman_2002 & $0.109^{* * *}$ & $(0.0208)$ & -0.0111 & $(0.00688)$ & 0.00473 & $(0.00421)$ \\
\hline D_pop_2005 & -0.0190 & $(0.0256)$ & $0.142^{* * *}$ & $(0.0465)$ & $0.133^{* * *}$ & $(0.0231)$ \\
\hline D_vcrops_2002 & -0.141 & $(0.261)$ & -0.349 & $(0.252)$ & -0.0411 & $(0.223)$ \\
\hline D_vlstk_2002 & 0.0333 & $(0.0655)$ & 0.0842 & $(0.0556)$ & $-0.194^{* * *}$ & $(0.0497)$ \\
\hline D_vman_2002 & 0.00103 & $(0.00165)$ & $-0.0124^{* * *}$ & $(0.00279)$ & $-0.00855^{* * *}$ & $(0.00136)$ \\
\hline CO_NA & 0.0131 & $(0.0302)$ & $0.568^{* * *}$ & $(0.0302)$ & $1.968^{* * *}$ & $(0.0331)$ \\
\hline O_corn_2002 & $-3.318^{*}$ & $(1.967)$ & 0.277 & $(1.026)$ & -0.0743 & $(0.727)$ \\
\hline D_refinery_dist & 0.0000834 & $(0.000203)$ & $-0.00179^{* * *}$ & $(0.000396)$ & -0.000353 & $(0.000295)$ \\
\hline RTD & $0.0449^{* *}$ & $(0.0187)$ & $-0.0384^{* * *}$ & $(0.0107)$ & -0.00841 & $(0.00699)$ \\
\hline O_interchng & $0.739^{* * *}$ & $(0.0388)$ & -0.0119 & $(0.0241)$ & -0.0118 & $(0.0164)$ \\
\hline D_interchng & 0.000276 & $(0.0228)$ & $0.285^{* * *}$ & $(0.0462)$ & $0.225^{* * *}$ & $(0.0280)$ \\
\hline Constant & 0.209 & $(0.214)$ & $2.687^{* * *}$ & $(0.150)$ & 0.0615 & $(0.0851)$ \\
\hline Mile X RR effects & Yes & & Yes & & Yes & \\
\hline Mile_sq X RR effects & Yes & & Yes & & Yes & \\
\hline state effects & Yes & & Yes & & Yes & \\
\hline Observations & 4413 & & 4413 & & 4413 & \\
\hline Adjusted $R^{2}$ & 0.535 & & 0.852 & & 0.912 & \\
\hline
\end{tabular}

Standard errors clustered on origin and destination price group in parentheses

${ }^{*} p<0.10,{ }^{* *} p<0.05,{ }^{* * *} p<0.01$ 
Table 5: OLS and 2SLS estimates of the effects of railroad participation and CO non-attainment status on prices

\begin{tabular}{|c|c|c|c|c|c|c|}
\hline & OLS & & Red. Smpl. & & 2 2SLS & \\
\hline & Coef. & Std. Err. & Coef. & Std. Err. & Coef. & Std. Err. \\
\hline Num_RR_org & $-0.0142^{* * *}$ & $(0.00281)$ & $-0.0116^{* * *}$ & $(0.00281)$ & $-0.0343^{* * *}$ & $(0.0104)$ \\
\hline Num_RR_dest & $-0.00456^{* *}$ & $(0.00223)$ & -0.00328 & $(0.00227)$ & -0.00127 & $(0.00241)$ \\
\hline CO_NA & $0.0170^{* * *}$ & $(0.00583)$ & $0.0331^{* * *}$ & $(0.00729)$ & $0.0539^{* * *}$ & $(0.0146)$ \\
\hline RR_dest_CO_NA & -0.00275 & $(0.00304)$ & $-0.00682^{* *}$ & $(0.00338)$ & $-0.0233^{* * *}$ & $(0.00804)$ \\
\hline $\mathrm{RR}==\mathrm{CN}$ & $-1.294^{* * *}$ & $(0.0775)$ & $-1.268^{* * *}$ & $(0.0723)$ & $-1.249^{* * *}$ & $(0.0737)$ \\
\hline $\mathrm{RR}==\mathrm{CSX}$ & $-0.460^{* * *}$ & $(0.0496)$ & $-0.492^{* * *}$ & $(0.0513)$ & $-0.441^{* * *}$ & $(0.0513)$ \\
\hline $\mathrm{RR}==\mathrm{NS}$ & $-0.543^{* * *}$ & $(0.116)$ & $-0.532^{* * *}$ & $(0.108)$ & $-0.498^{* * *}$ & $(0.106)$ \\
\hline $\mathrm{RR}==\mathrm{UP}$ & -0.0288 & $(0.0223)$ & -0.0309 & $(0.0238)$ & -0.0335 & $(0.0246)$ \\
\hline Miles & $0.000379^{* * *}$ & $(0.0000248)$ & $0.000364^{* * *}$ & $(0.0000249)$ & $0.000365^{* * *}$ & $(0.0000258)$ \\
\hline$(\mathrm{RR}==\mathrm{CN}) *$ miles & $0.00235^{* * *}$ & $(0.000325)$ & $0.00224^{* * *}$ & $(0.000309)$ & $0.00218^{* * *}$ & $(0.000304)$ \\
\hline$(\mathrm{RR}==\mathrm{CSX}) *$ miles & $0.000547^{* * *}$ & $(0.0000725)$ & $0.000565^{* * *}$ & $(0.0000759)$ & $0.000571^{* * *}$ & $(0.0000757)$ \\
\hline$(\mathrm{RR}==\mathrm{NS}) *$ miles & $0.00125^{* * *}$ & $(0.000453)$ & $0.00102^{* *}$ & $(0.000410)$ & $0.00109^{* * *}$ & $(0.000398)$ \\
\hline$(\mathrm{RR}==\mathrm{UP}) *$ miles & $0.000179^{* * *}$ & $(0.0000365)$ & $0.000190^{* * *}$ & $(0.0000378)$ & $0.000189^{* * *}$ & $(0.0000385)$ \\
\hline Miles_sq & $-0.000347^{* * *}$ & $(0.0000806)$ & $-0.000370^{* * *}$ & $(0.0000782)$ & $-0.000371^{* * *}$ & $(0.0000803)$ \\
\hline$(\mathrm{RR}==\mathrm{CN})^{*}$ miles_sq & $-0.0122^{* * *}$ & $(0.00313)$ & $-0.0113^{* * *}$ & $(0.00303)$ & $-0.0107^{* * *}$ & $(0.00295)$ \\
\hline$(\mathrm{RR}==\mathrm{CSX})^{*}$ miles_sq & $-0.00186^{* * *}$ & $(0.000463)$ & $-0.00186^{* * *}$ & $(0.000509)$ & $-0.00187^{* * *}$ & $(0.000504)$ \\
\hline$(\mathrm{RR}==\mathrm{NS}) *$ miles_sq & $-0.00649^{*}$ & $(0.00383)$ & -0.00416 & $(0.00342)$ & -0.00489 & $(0.00332)$ \\
\hline$(\mathrm{RR}==\mathrm{UP})^{*}$ miles_sq & $-0.000580^{* * *}$ & $(0.000133)$ & $-0.000647^{* * *}$ & $(0.000136)$ & $-0.000624^{* * *}$ & $(0.000139)$ \\
\hline RTD & $-0.0110^{* * *}$ & $(0.00256)$ & $-0.00933^{* * *}$ & $(0.00274)$ & $-0.00861^{* * *}$ & $(0.00284)$ \\
\hline O_interchng & $0.0245^{* * *}$ & $(0.00700)$ & $0.0269^{* * *}$ & $(0.00682)$ & $0.0496^{* * *}$ & $(0.0101)$ \\
\hline D_interchng & $0.0281^{* * *}$ & $(0.00532)$ & $0.0273^{* * *}$ & $(0.00504)$ & $0.0311^{* * *}$ & $(0.00487)$ \\
\hline O_corn_2002 & & & & & -0.106 & $(0.308)$ \\
\hline D_refinery_dist & & & & & $-0.000139^{* * *}$ & $(0.0000425)$ \\
\hline Constant & $8.024^{* * *}$ & $(0.0308)$ & $8.044^{* * *}$ & $(0.0329)$ & $7.999^{* * *}$ & $(0.0337)$ \\
\hline state effects & Yes & & Yes & & Yes & \\
\hline census controls & No & & No & & Yes & \\
\hline Observations & 5165 & & 4413 & & 4413 & \\
\hline Adjusted $R^{2}$ & 0.954 & & 0.960 & & 0.960 & \\
\hline
\end{tabular}

Standard errors clustered on origin and destination price group in parentheses

${ }^{*} p<0.10,{ }^{* *} p<0.05,{ }^{* * *} p<0.01$ 
Table 6: Robustness checks

\begin{tabular}{|c|c|c|c|c|c|}
\hline & Base Model & Density & No 3 RRs & Route & Levels \\
\hline Num_RR_org & $\begin{array}{c}-0.0343^{* * *} \\
(0.0104)\end{array}$ & $\begin{array}{c}-0.0358^{* * *} \\
(0.0105)\end{array}$ & $\begin{array}{c}-0.0267^{*} \\
(0.0146)\end{array}$ & & $\begin{array}{c}-146.6^{* * *} \\
(46.60)\end{array}$ \\
\hline Num_RR_dest & $\begin{array}{l}-0.00127 \\
(0.00241)\end{array}$ & $\begin{array}{l}0.000612 \\
(0.00247)\end{array}$ & $\begin{array}{c}0.0209 \\
(0.0201)\end{array}$ & & $\begin{array}{l}-5.113 \\
(8.375)\end{array}$ \\
\hline CO_NA & $\begin{array}{c}0.0539^{* * *} \\
(0.0146)\end{array}$ & $\begin{array}{c}0.0595^{* * *} \\
(0.0148)\end{array}$ & $\begin{array}{l}0.0742^{* *} \\
(0.0296)\end{array}$ & $\begin{array}{c}0.111^{*} \\
(0.0652)\end{array}$ & $\begin{array}{c}248.8^{* * *} \\
(58.63)\end{array}$ \\
\hline RR_dest_CO_NA & $\begin{array}{c}-0.0233^{* * *} \\
(0.00804)\end{array}$ & $\begin{array}{c}-0.0214^{* * *} \\
(0.00795)\end{array}$ & $\begin{array}{l}-0.0432^{*} \\
(0.0224)\end{array}$ & & $\begin{array}{c}-100.5^{* * *} \\
(32.78)\end{array}$ \\
\hline Num_RR_route & & & & $\begin{array}{r}-0.00982 \\
(0.0453)\end{array}$ & \\
\hline RR_route_CO_NA & & & & $\begin{array}{l}-0.0919 \\
(0.0621)\end{array}$ & \\
\hline Org_density & & $\begin{array}{c}0.000649 \\
(0.000590)\end{array}$ & & & \\
\hline Dest_density & & $\begin{array}{l}0.00377^{* * *} \\
(0.000615)\end{array}$ & & & \\
\hline Mile X RR effects & Yes & Yes & Yes & Yes & Yes \\
\hline Mile_sq X RR effects & Yes & Yes & Yes & Yes & Yes \\
\hline state effects & Yes & Yes & Yes & Yes & Yes \\
\hline census controls & Yes & Yes & Yes & Yes & Yes \\
\hline Observations & 4413 & 4413 & 3886 & 4413 & 4413 \\
\hline Adjusted $R^{2}$ & 0.960 & 0.960 & 0.961 & 0.956 & 0.962 \\
\hline
\end{tabular}

Standard errors clustered on origin and destination price group in parentheses

${ }^{*} p<0.10,{ }^{* *} p<0.05,{ }^{* * *} p<0.01$ 